\title{
COMPARATIVE EVALUATION OF VASCULAR ENDOTHELIUM MICROCIRCULATION PARAMETERS AND FUNCTIONAL CONDITION IN PATIENTS WITH GENERALIZED PERIODONTITIS OF CHRONIC AND RAPIDLY-PROGRESSIVE COURSE
}

\section{Natalia Bulkina', Evgeny Shastin', Anna Vedyaeva3, Yulia Osipova ${ }^{1}$, Valeriy Konnov ${ }^{4}$}

\author{
${ }^{1}$ Department of Therapeutic Dentistry, Saratov State Medical University, \\ Saratov \\ 2 Dental clinic "Dentik Lux", Krasnodar, Russia \\ ${ }^{3}$ Department of Dentistry, Sechenov University; Department of \\ Periodontology, Central Research Institute of Dental and Maxillofacial \\ Surgery, Moscow, Russia \\ ${ }^{4}$ Department of Orthopedic Dentistry; Saratov State Medical University, \\ Saratov, Russia
}

$\triangle$ navo@bk.ru

\begin{abstract}
The article offers a view at the results of a survey involving patients with generalized periodontitis of a rapidly progressive course compared with patients suffering from generalized periodontitis of a chronic course using laser Doppler flowmetry with identification of blood flow speed indicators and the level of endothelial factors expression. The data obtained shows that the imbalance between the development of vasodilators and vasoconstrictors towards an increase in the latter is a manifestation of vascular endothelial dysfunction of the periodontal complex, and, in our opinion, leads to a rapid progress of inflammation in it.
\end{abstract}

KEYW ORDS - generalized periodontitis of chronic and rapidly progressive course, laser Doppler flowmetry, vascular endothelial dysfunction.

\section{INTRODUCTION}

Inflammatory periodont diseases are a serious issue faced by dentistry nowadays, which is due to the multifactor etiology, the complex pathogenesis, short effect of most therapeutic measures. At the same time, aggressive periodontitis is increasingly common, in particular, rapidly progressive periodontitis (RPP), which has an almost continuously recurring course. RPP develops within 3-5 years, sometimes over several months, leading to a generalization of the process, severe inflammation, bleeding, bad breath, alveolar processes bone tissue lysis, loss of teeth, with frequent exacerbations and short remissions [1, 2, 6]. Given the polyethiological cause behind RPP, its treatment involves significant difficulties, which include greater resistance to interventions, and, accordingly, longer treatment with poorer outcomes $[5,10-15]$.

Bacterial invasion plays a leading role in the pathogenesis of aggressive types of periodontitis; however, antibiotic ethiotropic therapy of periodontitis does not offer long-term remission or complete recovery, which indicates involvement of some other, no less important mechanisms behind the development of the pathology, which include disorders in the periodontal microcirculation system $[4,7,8,9]$. There are some works available focusing on the status of the hemostasis system microcirculatory component (the functional activity of red blood cells, platelets and thrombotic resistance of the vascular wall endothelium) in patients with RPP, which contribute to understanding the RPP pathogenesis mechanisms and the role that microcirculatory disorders play in the progression of this disease, which might serve a criterion for evaluating the effectiveness of the available therapeutic measures [3].

Aim of study:

to carry out comparative assessment of microcirculation parameters and the functional state of the vascular wall endothelium in patients with generalized periodontitis of a chronic and rapidly progressing course.

\section{MATERIAL AND METHODS}

Laser Doppler flowmetry was used to study blood flow speed indicators as well as the level of endothelial factors expression in patients with rapidly progressing generalized periodontitis (main group, $\mathrm{n}=20$ ) compared to patients with chronic generalized periodontitis (comparison group, $\mathrm{n}=20$ ); the control group of basically healthy individuals included 20 people. The following indicators of the periodontal tissues microcirculation were studied: $\mathrm{M}$ - arithmetic mean value of the microcirculation index (PF unit); $\sigma$ - the rootmean-square deviation of the blood flow fluctuations amplitude from the arithmetic mean value (PF unit); $\mathrm{Kv}$ - variation coefficient (\%).

Statistical processing of the results was carried out through parametric and non-parametric analysis using the "Statistica 8.0 for Windows" (StatSoft-Russia) and 
Microsoft OfficeExelle 2007 software packages. The differences between the samples were evaluated with the Student $t$-test (in case of normal distribution of variables) and Mann-Whitney U-criterion (in case of lack of data coherence with normal distribution). The relationship between quantitative traits was studied using the Pearson correlation coefficient or the Spearman rank correlation coefficient, the critical significance level of $p$ being at $<0.05$.

\section{RESULTS AND DISCUSSION}

The obtained results showed that patients, both the comparison group and the main group, revealed significant changes in the functional state of the periodontal tissues microvasculature. The changes were primarily associated with disturbed peripheral tissue perfusion and a decrease in the vasomotor activity of microvessels, which was reflected in a significant decrease in the average perfusion rate to $14.06 \pm 0.74 \mathrm{PF}$ units. in patients with generalized periodontitis of a chronic course, and $12.01 \pm 0.50 \mathrm{PF}$ units - in patients with rapidly progressive periodontitis $(\mathrm{p}<0.05)$, a decrease in the perfusion index mean square deviation was to $1.17 \pm 0.14 \mathrm{PF}$ units and $1.01 \pm 0.03 \mathrm{PF}$ units; variation coefficient - to $10.55 \pm 0.53 \%$ and $8.92 \pm 0.40 \%$, respectively.

Therefore, in case of generalized periodontitis, regardless of the course, there was disturbed periodontal tissues microcirculation identified, which featured pathological dilatation of the vessels, an increase in their permeability with the development of perivascular edema, impaired transcapillary metabolism and, as a consequence, the development of gum tissue hypoxia. The indicated pattern of microcirculatory disorders was more severe in patients with generalized periodontitis of a rapidly progressive course. A consequence of these microcirculatory disorders was a decrease in the rate of capillary blood flow, as well as in the number of functioning capillaries (due to a significant perfusion rate decrease) and vascular depletion of the periodontal tissues microvasculature.

The changes observed in periodontal tissues microcirculation in patients of the studied groups are directly related to changes in the vascular wall endothelium functioning as well as to a significant imbalance of bioactive substances secreted by it. The data obtained showed that, compared with the control group of virtually healthy individuals, patients with generalized periodontitis had statistically significantly reduced content of endothelial nitric oxide synthase (eNOS) and nitrite ions in the blood plasma, whose total concentration has been generally accepted as an indicator to be employed when assessing the eNOS activity and the nitric oxide production in the vascular endothelium.
In our study, patients of both groups showed an increase in the concentration of bioactive substances with vasoconstrictor activity - dimethylarginine (ADMA) and endothelin (1-38, big) along with a functional deficit of a group of substances featuring a vasodilating function (eNOS, nitrite ions) (see Table 1).

\section{CONCLUSION}

In view a the above, the imbalance between the vasodilators and vasoconstrictors development leaning towards an increase in the latter is undoubtedly a manifestation of vascular periodontal endothelial dysfunction, and, as we see it, leads to rapid progress of the inflammatory development in it. This idea is enforced with statistically significant differences demonstrated by these indicators if matched against the control group's values, compared with patients of the comparison group and the main group $(\mathrm{p}<0.05)$. Besides, there was a statistically significant difference observed between these indicators in patients with generalized periodontitis of chronic and that of rapidly progressing course $(\mathrm{p}<0.05)$.

\section{REFERENCES}

1. BULKINA, N. V. Immunohistochemical criteria for the effectiveness of complex treatment of patients with rapidly progressive periodontitis using combined physiotherapeutic methods / N.V. Bulkina, L.V. Bashkova // Dental South. - 2009. - No.9 (69). - P. 15-17. (In Russ.).

2. Bulkina N.V. Rapidly progressive periodontitis: new aspects of pathogenesis and complex therapy // Periodontology. 2012. No. 4 (65). P. 13-18. (In Russ.).

3. Zelenova, A. V. The effectiveness of the use of electromagnetic radiation in the terahertz range in the complex therapy of rapidly progressive periodontitis / A. V. Zelenova, N. V. Bulkina, E.S. Olenko, E.V. Tokmakova / Saratov Journal of Medical Scientific Research. - 2015. - No. 4. - P. 556-561.(In Russ.).

4. Bulkina N.V., Zelenova A.V., Tokmakova E.V., BASHKOVA L.V. Modern aspects of the treatment of hemodynamic disorders in patients with rapidly progressive periodontitis / Modern problems of science and education. - 2014. - No. 6. - 1046 p. (In Russ.).

5. Modina T.N., Ganzha I.R., Mamaev E.V. Treatment of aggressive periodontitis: a clinical case, tenyear follow-up // Clinical Dentistry. 2017. No. 4 (84). P. 18-21. (In Russ.).

6. Orekhova L.Yu., Loboda E.S., Oboeva M.L. Photodynamic therapy in the complex treatment of inflammatory periodontal diseases / / Periodontology. 2015. No. 20 (1). P. 44-50. (In Russ.).

7. Akimova S.A., Bulkina N.V., Osipova Yu.L., Ostrovskaya L.Yu., ZyUlkina L.A., Vedyaeva A.P., Konnov V.V. Gingival mucosa proliferative 
Table 1. The functional status of vascular wall endothelium in patients of the studied groups

\begin{tabular}{l|l|l|l|l}
\hline Duration of observation & eNOS, $\mathrm{pg} / \mathrm{ml}$ & nitrites, $\mathrm{mcg} / \mathrm{ml}$ & $1-38$, big, pmol / & ADMA, $\mu \mathrm{mol} / \mathrm{L}$ \\
\hline Control Group, $\mathrm{n}=20$ & $443,01 \pm 2,07$ & $0,74 \pm 0,20$ & $0,87 \pm 0,06$ & $0,38 \pm 0,12$ \\
\hline Comparison group, $\mathrm{n}=20$ & $380,22 \pm 3,33^{*}$ & $0,55 \pm 0,08^{*}$ & $0,96 \pm 0,06^{*}$ & $0,50 \pm 0,09^{*}$ \\
\hline Main group, $\mathrm{n}=20$ & $374,12 \pm 3,03 \#$ & $0,45 \pm 0,05 \#$ & $1,1 \pm 0,08 \#$ & $0,59 \pm 0,11 \#$ \\
\hline
\end{tabular}

Note. * — statistically significant differences with the respective indicator in the group of healthy individuals; \# — statistically significant differences with the respective indicator in the comparison group ( $U-$ Mann-Whitney test, $p<0.05)$.

activity and epitheliocytes apoptosis indicators in patients with rapidly progresing periodontitis // Archiv EuroMedica. 2019. Vol. 9. № 2. P. 130-133.

8. Bulkina N.V., Osipova Yu.L., Guseva O.Yu., Morgunova V.M., Kitaeva V.N., Polosukhina E.N., KonNov V.V. Disturbed cell proliferation and apoptosis in patients with chronic periodontitis against the background of gastroesophageal reflux disease // Archiv EuroMedica. 2019. Vol. 9. № 3. P. 97-100. https://doi.org/10.35630/2199$885 \mathrm{X} / 2019 / 9 / 3.27$

9. Bulkina N.V., Morgunova V.M., Osipova Yu.L., Pronina N.S., Polosukhina E.N., Guseva O.Yu., Kropotina A.Yu., KonNov V.V. Cytokine profile of periodontal pocket contents in estimating the severity and efficiency of treatment offered to patients with refractory periodontitis // Archiv EuroMedica. 2019. Vol. 9. № 2. P. 133-136.

10. Bulkina N.V., Makarova N.I., IVANOV P.V., LEBEDEV M.V., Zyulkina L.A., Shastin E.N., KonNOV V.V. Modern methods of non-invasive correction for disturbed regional blood circulation through physiotherapeutic measures (Literature Review) // Archiv EuroMedica. 2019. Vol. 9. № 2. P. 17-22.

11. Davydov B.N., Domenyuk D.A., DMitrienko S.V. Peculiarities of microcirculation in periodont tissues in children of key age groups sufficient type 1 diabetes. Part I. Periodontology, 2019; Vol. 24; 1-24(90): 4-10. DOI: 10.25636/PMP.1.2019.1.1

12. Davydov B.N., Domenyuk D.A., DMitrienko S.V. Peculiarities of microcirculation in periodont tissues in children of key age groups sufficient type 1 diabetes. Part II. Periodontology. 2019;24(2):108-119. (In Russ.) DOI:10.33925/1683-3759-2019-24-2-108-119

13. Davydov B.N., Domenyuk D.A., BYkov I.M., IVCHENKo L.G., DMitrienko S.V. Modern possibilities of clinical-laboratory and $\mathrm{x}$-ray research in preclinical diagnostics and prediction of the risk of development of periodontal in children with sugar diabetes of the first type. Part I. Periodontology, 2018; Vol. 23; 3-23(88): 4-11. DOI:10.25636/PMP.1.2018.3.1

14. Domenyuk D.A., Porfyriadis M.P., BudayCHIEV G. M-A. Contemporary methodological approaches to diagnosing bone tissue disturbances in children with type 1 diabetes. Archiv EuroMedica, 2018; 8(2): 71-81.
15. Domenyuk D.A., SAmedov F., Dmitrienko S.V., Anfinogenova O.I., Glizhova T.N., Lysan D., Nuzhnaya CH. Matrix metalloproteinases and their tissue inhibitors in the pathogenesis of periodontal diseases in type 1 diabetes mellitus // Archiv EuroMedica. 2019. Vol. 9. № 3. P. 81-90. https://doi. org/10.35630/2199-885X/2019/9/9/3.25 